\title{
Estudantes de Odontologia cotistas e o instrumental odontológico
}

\author{
Ângela Barbosa Martins*; Ida Helena Carvalho Francescantonio Menezes**; Maria Goretti \\ Queiroz***
}

* Mestranda, Programa de Pós-Graduação em Ensino na Saúde, Faculdade de Medicina, Universidade Federal de Goiás

** Professora Doutora, Faculdade de Nutrição, Programa de Pós-Graduação em Ensino na Saúde, Universidade Federal de Goiás

*** Professora Doutora, Faculdade de Odontologia, Programa de Pós-Graduação em Ensino na Saúde, Universidade Federal de Goiás

Recebido em 13/09/2018. Aprovado em 23/09/2019.

\begin{abstract}
RESUMO
A Política de Cotas para o ensino superior no Brasil propõe a reserva de vagas para estudantes oriundos de escolas públicas, pretos, pardos, indígenas e de baixo poder aquisitivo. A aquisição do instrumental exigido no curso de Odontologia representa uma dificuldade para a permanência da maioria desses estudantes. O objetivo deste estudo foi conhecer a experiência de cotistas em relação à aquisição e uso dos instrumentais e materiais para as aulas práticas de um curso de graduação em Odontologia. Foi realizada pesquisa de abordagem qualitativa, por meio de entrevistas semiestruturadas, com 16 estudantes de todos os anos do curso, de todas as modalidades de cotas segundo a Lei 12.711/2012, escolhidos de forma aleatória. O tratamento dos dados baseou-se na modalidade temática da Análise de Conteúdo, de onde emergiram três categorias: "Inclusão", "Exclusão" e "Discriminação". O apoio da comunidade universitária, família e colegas figura como mecanismo de inclusão, por favorecer a permanência desses estudantes, assim como o programa de empréstimo de instrumental a estudantes de baixa renda dessa Universidade. Por outro lado, o programa também foi considerado fator de exclusão por não oferecer todo instrumental solicitado e alguns apresentarem baixa qualidade. Os entrevistados relataram sofrer discriminação, por pequena parte dos professores, e se sentirem excluídos quando utilizam instrumentos fora do padrão exigido. O desafio para a instituição pesquisada é garantir as adequadas condições materiais para o aprendizado desses estudantes, propor estratégias para a melhoria do programa de instrumental e implementar ações visando à capacitação docente.
\end{abstract}

Descritores: Ação Afirmativa. Estudante de Odontologia. Odontologia. Política Pública. Universidades. 


\section{INTRODUÇÃO}

A Política de Cotas para o ensino superior no Brasil é um tipo de ação afirmativa que propõe a inclusão de estudantes que historicamente encontraram dificuldades para o ingresso nas Instituições Federais de Ensino Superior (IFES), especialmente nos cursos mais concorridos $\mathrm{e}$ geralmente considerados de maior prestígio social, como a Odontologia ${ }^{1,2}$. Especificamente para esse curso, tal política trouxe o enfrentamento da dificuldade de aquisição do instrumental e material odontológico.

Políticas de reserva de vagas para estudantes de escolas públicas e negros começaram a ser implementadas nas universidades brasileiras a partir do ano de $2002^{3}$. A Universidade onde esta pesquisa foi realizada instituiu em 2009 um sistema de reserva de vagas para estudantes de escolas públicas que se autodeclarassem negros e para indígenas ou quilombolas.

Em 2012 foi sancionada a Lei $12.711^{4}$, após diversas experiências de cotas para o ensino superior no Brasil e intensos debates na mídia, no âmbito das universidades e na sociedade em geral ${ }^{3,5}$. Em relação às Universidades Públicas Federais, a Lei 12.711/2012 estabelece que todas as Instituições Federais de Ensino Superior destinem 50\% das vagas para estudantes que cursaram o ensino médio em escolas públicas. Ainda determina que a distribuição dessas vagas deve considerar o percentual de pretos, pardos e indígenas no estado onde se situa a IFES, segundo o último censo do Instituto Brasileiro de Geografia e Estatística (IBGE), como também a renda familiar. Após a Lei 12.711/2012, o Programa de Inclusão dessa Universidade ainda continuou destinando uma vaga para indígenas e outra para quilombolas.

Os estudantes beneficiários de cotas muitas vezes se apresentam em desvantagem quando são consideradas as condições econômicas, sociais, educacionais e culturais com as quais adentram a universidade ${ }^{5}$. Resende, Queiroz e Faria $(2012)^{6}$ e a última pesquisa publicada do Fórum Nacional de
Pró-Reitores de Assuntos Estudantis (FONAPRACE) ${ }^{7}$ revelam as disparidades entre os estudantes, considerando o curso que frequentam. Diferem no poder aquisitivo e, consequentemente, nas condições de atender a necessidades materiais, como livros, fotocópias, instrumentos necessários para a aprendizagem prática, transporte, entre outros. Condições que destoam ainda mais ao se observar o perfil de ingressantes dos cursos mais concorridos das IFES.

Estudantes oriundos de famílias com baixo poder aquisitivo enfrentam dificuldades variadas durante todo o curso, como as relacionadas à alimentação, moradia, locomoção até a universidade, aproveitamento acadêmico, convívio no ambiente universitário ${ }^{8,9}$

Nesse sentido, a exigência de um oneroso conjunto de instrumentos no curso de Odontologia é um desafio para a permanência desses estudantes na Universidade. Na Faculdade de Odontologia do presente estudo, há um programa de empréstimo de instrumental a estudantes de baixa renda, como política institucional para sua permanência. Essa política é subsidiada pelo Plano Nacional de Assistência Estudantil (PNAES), regulamentado pelo decreto $\mathrm{n}^{\mathrm{o}} 7.234$, de $2010^{10}$.

Diante dessa realidade, o presente estudo objetiva conhecer a experiência dos estudantes cotistas em relação à aquisição e uso de instrumentais e materiais para as aulas práticas de um curso de graduação em Odontologia.

\section{METODOLOGIA}

Este estudo é de abordagem qualitativa, uma vez que se propôs a estudar as relações, opiniões e percepções de um grupo delimitado ${ }^{11}$. Foi realizado em uma Faculdade de Odontologia e obteve a aprovação do Comitê de Ética sob o número do parecer 1.723.122.

A Pró-Reitoria de Graduação dessa universidade forneceu a lista com 162 estudantes beneficiários de cotas por ano, gênero, tipo de cotas e situação de matrícula, ingressos desde o ano de 
2009 até 2017, ano da coleta de dados para este estudo. Os critérios de inclusão utilizados para a escolha dos participantes foram: ser estudante que ingressou pelo Programa de Inclusão da Universidade ou pela Lei 12.711/2012 e estar regularmente matriculado no curso, no semestre em que ocorreu a coleta de dados. Os critérios de exclusão foram: estar em licença maternidade, ter matrícula trancada ou processo de exclusão da Universidade. Estavam aptos a participarem da pesquisa 111 estudantes.

Os participantes da pesquisa foram selecionados de forma aleatória. $\mathrm{O}$ contato com os estudantes foi via e-mail ou pelo aplicativo de comunicação instantânea de mensagens, via telefone celular, denominado Whatsapp. Inicialmente, foram contatados 17 estudantes, sorteados de acordo com o ano do curso, dos quais 11 aceitaram participar da pesquisa. Foi realizado um sorteio de mais cinco estudantes, visando ao equilíbrio da representatividade dos tipos de cotas, do ano de ingresso e do sexo, com a finalidade de coletar dados que contemplassem a pluralidade da população da pesquisa e das experiências dos estudantes nas diversas fases do curso. Ao final, foram entrevistados 16 participantes (tabela 1).

Tabela 1. Número total de estudantes entrevistados segundo o tipo de cota

\begin{tabular}{|c|c|c|c|c|c|c|c|c|c|c|c|c|c|c|c|c|c|c|c|}
\hline \multirow{2}{*}{$\begin{array}{l}\text { Tipos de } \\
\text { cotas }\end{array}$} & \multicolumn{2}{|c|}{2009} & \multicolumn{2}{|c|}{2010} & \multicolumn{2}{|c|}{2011} & \multicolumn{2}{|c|}{2012} & \multicolumn{2}{|c|}{2013} & \multicolumn{2}{|c|}{2014} & \multicolumn{2}{|c|}{2015} & \multicolumn{2}{|c|}{2016} & \multicolumn{2}{|c|}{2017} & \multirow[b]{2}{*}{ Total } \\
\hline & $\mathbf{M}$ & $\mathbf{F}$ & $\mathbf{M}$ & $\mathbf{F}$ & $\mathbf{M}$ & $\mathbf{F}$ & $\mathbf{M}$ & $\mathbf{F}$ & M & $\mathbf{F}$ & $\mathbf{M}$ & $\mathbf{F}$ & $\mathbf{M}$ & $\mathbf{F}$ & $\mathbf{M}$ & $\mathbf{F}$ & $\mathbf{M}$ & $\mathbf{F}$ & \\
\hline PI* & & 1 & & 1 & & 1 & 1 & 1 & & & & & & & & 1 & & & 6 \\
\hline $\mathrm{PPI}-\mathrm{RI}{ }^{* *}$ & & & & & & & & & & & & 1 & & & & & & & 1 \\
\hline PPI-RS*** & & & & & & & & & & 1 & & & 1 & & & & & 1 & 3 \\
\hline $\mathrm{DC}-\mathrm{RI} * * * *$ & & & & & & & & & & & 1 & & & & & 1 & 1 & & 3 \\
\hline $\mathrm{DC}-\mathrm{RS} * * * * *$ & & & & & & & & & 1 & & & & & & 1 & 1 & & & 3 \\
\hline Totais & & 1 & & 1 & & 1 & 1 & 1 & $\mathbf{1}$ & 1 & $\mathbf{1}$ & 1 & 1 & & $\mathbf{1}$ & 3 & $\mathbf{1}$ & $\mathbf{1}$ & 16 \\
\hline
\end{tabular}

* PI- Programa de Inclusão instituído por essa Universidade, para grupo de estudantes oriundos da Escola Pública, Negros oriundos da Escola Pública, Indígenas e Quilombolas, com prevalência a partir de 2009.

**PPI-RI - Lei 12.711, com prevalência a partir de 2012, para grupos de Pretos, Pardos e Indígenas oriundos de Escola Pública, com Renda Familiar Inferior a 1,5 Salário Mínimo.

***PPI-RS - Lei 12.711, com prevalência a partir de 2012, para grupos de Pretos, Pardos e Indígenas oriundos de Escola Pública, com Renda Familiar Superior a 1,5 Salário Mínimo.

****DC-RI - Lei 12.711, com prevalência a partir de 2012, para grupo dos Demais Concorrentes oriundos da Escola Pública com Renda Familiar Inferior a 1,5 Salário Mínimo.

*****DC-RS - Lei 12.711, com prevalência a partir de 2012, para grupo dos Demais Concorrentes oriundos da Escola Pública com Renda Familiar Superior a 1,5 Salário Mínimo.

A técnica escolhida para a coleta de dados foi a entrevista semiestruturada e o instrumento utilizado foi um roteiro construído pela pesquisadora. A primeira parte continha questões iniciais de identificação dos estudantes, como data de nascimento, ano de ingresso, autodeclaração em relação à raça ou etnia, experiências de escolaridade antes do ingresso na universidade, trabalho, moradia e participação em atividades de pesquisa e extensão.

A segunda parte do roteiro continha oito perguntas que buscavam conhecer as experiências vivenciadas pelos estudantes durante o curso. Entre as várias dimensões que emergiram das falas dos participantes, para este artigo foi escolhida a dimensão instrumental e material odontológico.

Para análise dos dados, optou-se pela modalidade Temática da Análise de Conteúdo, segundo Bardin ${ }^{12}$. A Análise de Conteúdo é um conjunto de técnicas. Entre elas, a modalidade temática é aquela que "se direciona para as características da mensagem propriamente dita, seu valor informacional, as palavras, argumentos e ideias nela expressos" (p. 3) ${ }^{13}$. Prevê um método de ordenação, classificação e categorização dos dados coletados até a obtenção de categorias mais amplas que representem todo conteúdo expresso nos dados 
coletados $^{14}$. Inicialmente foi feita uma leitura das entrevistas e a criação de um arquivo com as respostas de cada pergunta do roteiro. Em seguida, foram elencados os fragmentos mais significativos $\mathrm{e}$ extraídas as ideias centrais, seguindo o objetivo da pesquisa. A partir das ideias centrais, foram definidos os núcleos de sentido. Agrupando-se os núcleos de sentido pela similitude de seus conteúdos, emergiram três categorias temáticas: "Inclusão"; "Exclusão"; "Discriminação".

A categoria temática "Inclusão" refere-se às ações e aos meios que possibilitam aos estudantes a conclusão do curso com êxito. Neste artigo, diz respeito à forma de aquisição do instrumental e material exigidos para as aulas práticas e ao apoio que recebem da comunidade universitária, dos familiares e colegas. A categoria temática "Exclusão" refere-se às situações, padrões e atitudes que dificultam a permanência dos entrevistados, aqui representados por suas condições sóciohistórico-econômico-culturais e pelos desafios e dificuldades da Universidade em manter e ampliar seu programa de empréstimo de instrumental odontológico. A terceira categoria temática diz respeito à "Discriminação", que foi entendida como uma situação em que indivíduos ou membros de determinados grupos são prejudicados ou ficam em desvantagem social ou quando outros se beneficiam injustamente dessa situação ${ }^{15}$. Neste estudo, essa categoria faz referência às atitudes discriminatórias de alguns docentes em relação ao tipo de instrumental utilizado pelo aluno.

Este processo de categorização dos dados foi realizado pela pesquisadora principal e supervisionado pelas orientadoras da dissertação de mestrado da qual se originou o presente artigo.

\section{RESULTADOS E DISCUSSÃO}

Com o objetivo de conhecer a experiência dos estudantes cotistas em relação à aquisição e uso de instrumentais e materiais para as aulas práticas de um curso de graduação em Odontologia, os dados coletados foram categorizados e serão apresentados de acordo com o quadro 1.

Antes da apresentação do conteúdo do quadro 1, julgou-se importante trazer os dados de identificação e caracterização dos participantes desta pesquisa. Foram entrevistadas dez mulheres $(62,50 \%)$ e seis homens $(37,50 \%)$. A idade dos participantes variou de 19 a 35 anos, sendo que a média foi de 22,88 anos. Dos dezesseis entrevistados, sete se declararam pardos $(43,75 \%)$, três brancos $(18,75 \%)$, um indígena $(6,25 \%)$ e cinco negros $(31,25 \%)$, sendo um negro quilombola. Quanto ao tipo de escola onde cursaram o ensino médio, 14 estudantes vieram da escola pública estadual, sendo que desses, quatro estudaram em escolas militares. Dois estudantes fizeram o ensino médio em Instituto Federal de Educação. Quanto à moradia, nove moravam com a família e um relatou morar com um parente. Dois moravam em Casa de Estudante da Universidade, dois em casa que eles próprios alugaram e dois moravam em local alugado pela família. Metade dos entrevistados relatou participação em projetos de pesquisa e extensão.

A caracterização dos entrevistados revela similaridades com trabalhos que analisaram o perfil de estudantes de Odontologia, apesar de esses estudos não serem com beneficiários de cotas. Nos trabalhos acessados, a maioria eram mulheres, jovens, solteiros.

Toassi et al. $(2011)^{16}$ investigaram 360 estudantes na Universidade Federal do Rio Grande do Sul (UFRGS) e encontraram que a maioria era solteiro/a, jovem, sem filhos, com predomínio de mulheres, que nunca trabalharam, de famílias com alto nível de escolaridade e que estudaram em escolas particulares antes do ingresso no ensino superior.

Ristoff $\quad(2013)^{17}$ analisou o perfil socioeconômico dos respondentes dos dois primeiros ciclos do Exame Nacional de Desempenho dos Estudantes (Enade), tendo constatado que a Odontologia está entre os cursos com maior proporção de brancos e menor 
proporção de pardos, e com menor índice de estudantes oriundos de escolas públicas. No entanto, ao considerar esses dois últimos dados, é preciso observar que essa análise foi feita antes da promulgação da Lei $12.711 / 2012^{4}$. O autor encontrou também que $85 \%$ dos estudantes desse curso não trabalhavam e seus gastos eram financiados pela família.

Quadro 1. Categorização dos dados

\begin{tabular}{|c|c|c|}
\hline Categorias & Núcleos de Sentido & Ideias Centrais \\
\hline \multirow[t]{2}{*}{ Inclusão } & $\begin{array}{l}\text { Mecanismos de } \\
\text { Inclusão }\end{array}$ & $\begin{array}{l}\text { Inclusão pelo programa de empréstimo de instrumental; } \\
\text { Envolvimento e ajuda da direção da faculdade; Apoio da } \\
\text { coordenação do curso; Não há diferença no tratamento a cotistas. }\end{array}$ \\
\hline & Solidariedade & $\begin{array}{l}\text { Incentivo e apoio familiar; Solidariedade entre cotistas; } \\
\text { Solidariedade entre colegas. }\end{array}$ \\
\hline Exclusão & Fatores de Exclusão & $\begin{array}{l}\text { Luta constante pela permanência; Exclusão pela dificuldade em } \\
\text { adquirir instrumental necessário; Exclusão pela condição do } \\
\text { instrumental emprestado pela Universidade; Exclusão pela } \\
\text { condição social; Dificuldade financeira; Permanência mais difícil } \\
\text { que ingresso. }\end{array}$ \\
\hline Discriminação & Discriminação & $\begin{array}{l}\text { Constrangimento pelas questões relacionadas ao instrumental } \\
\text { utilizado no curso; Humilhação. }\end{array}$ \\
\hline
\end{tabular}

\section{Inclusão}

O programa de empréstimo de instrumental odontológico da Universidade, mantido com os recursos federais via PNAES $^{10}$, foi considerado pelos estudantes uma importante ação de permanência. Há uma ação conjunta da Faculdade de Odontologia com a Pró-Reitoria de Assuntos Estudantis (PRAE), em vigor desde o ano de 2010, que tem por objetivo emprestar o instrumental aos alunos que apresentem dificuldade financeira em adquiri-los. Os assistentes sociais da PRAE recebem a solicitação dos estudantes, traçam o perfil socioeconômico dos mesmos com base em entrevista e em documentos exigidos, e então selecionam os que serão contemplados pelo projeto. Na época da coleta de dados, sete entrevistados se utilizavam desse programa. Um deles disse que se não fosse ele, eu teria trancado $o$ curso (E2) e outro disse que o restante do instrumental, tudo foi fornecido pela faculdade (E5).

Esse tipo de política de permanência é importante e outras IFES também desenvolvem ações no sentido de favorecer que estudantes de baixa renda concluam o curso de Odontologia com êxito. Pode-se encontrar programas similares nas Universidades Federal do Pará $\left(\right.$ UFPA) ${ }^{18}$, do Maranhão (UFMA) ${ }^{19}$, de Uberlândia $(\mathrm{UFU})^{20}$. Todos esses programas são financiados pelo PNAES $^{10}$ e são importantes políticas de permanência para os estudantes de baixa renda.

Os entrevistados do presente estudo afirmaram que a direção da faculdade, a coordenação do curso, a maioria dos professores e os técnico-administrativos se esforçam em orientar os estudantes e buscar soluções para as dificuldades com a aquisição e o uso dos instrumentais e materiais odontológicos exigidos no curso, como no relato a seguir: Mas eu sempre me senti acolhida assim, por todos aqui, tanto meus colegas de curso, quanto pelos professores, técnicos, tudo mais (E5).

Os estudantes realçaram o apoio da família durante $\mathrm{o}$ curso $\mathrm{e}$ as diversas formas para conseguirem as adequadas condições materiais para o êxito da formação acadêmica.

(...) a gente pega emprestado duma madrinha minha...do meu avô... a minha mãe pega um empréstimo(...) e dá para comprar [o instrumental] (E7).

A solidariedade entre colegas e 
especialmente entre os cotistas também foi bastante mencionada, como por esse estudante que não se utilizava do empréstimo da universidade e relatou que comprava o mínimo possível e pegava emprestado [com colegas] (E13) e outro beneficiado pelo programa de empréstimo que disse que entre cotistas a gente se ajuda muito (E2).

Mayorga e Souza (2012) ${ }^{21}$ mencionam a presença de uma rede de suporte aos estudantes de baixa renda, formada por familiares, amigos, empregadores e também as várias estratégias utilizadas para os ajudar na conclusão do curso. As autoras afirmam ainda a formação de um grupo entre os iguais, referindo-se ao apoio entre os bolsistas de menor poder aquisitivo da UFMG, o que também foi encontrado entre os cotistas e os estudantes de baixa renda deste estudo.

\section{Exclusão}

O curso de Odontologia necessita de uma ampla lista de instrumentais e materiais para as aulas práticas, além do vestuário adequado que consiste em sapato branco fechado, roupa branca e jaleco branco de manga comprida. Um entrevistado comenta que a odontologia é um curso que requer muito dinheiro, a pessoa tem que comprar, comprar, comprar (E12), referindo-se ao alto valor financeiro de tudo o que é exigido ${ }^{22}$.

As dificuldades em relação à aquisição do instrumental e dos materiais se iniciam nos primeiros períodos do curso. É uma preocupação constante entre estudantes provenientes de famílias de baixa renda e um grande desafio para $80 \%$ dos entrevistados.

O custo financeiro do curso é considerado até mesmo um impedimento para a permanência de estudantes de baixa renda ${ }^{23}$ e para estudantes do ensino médio, no momento de optarem pela Odontologia ${ }^{24}$. Santos et al. $(2015)^{24}$ realizaram um levantamento em uma universidade pública a respeito do valor da lista completa dos instrumentais e estimaram um alto investimento financeiro para cada estudante durante todo o curso, o que correspondia em 2014 a aproximadamente 24 salários mínimos da época. Tal investimento causou espanto em um entrevistado que relatou: [...] na semana do calouro, teve uma palestra e aí a professora explicava, botava uma tabela lá (...) Uma estimativa de gastos, aí todos os pais tavam lá e ficaram assustados, mas meus pais não tavam lá. (...) E eu lembro de ir pra casa e chorar com medo de ter que voltar pra casa, desistir do curso, porque era realmente um valor muito alto (E13).

Esse tema é tão relevante que os recursos do GraduaCEO $^{25}$, programa que compõe a Política Nacional de Saúde Bucal, podem ser destinados à compra de instrumental odontológico. $\mathrm{O}$ artigo de Morita et al $(2016)^{26}$ apresenta um estudo da Associação Brasileira de Ensino em Odontologia (ABENO) que, de acordo com os autores, resultou em uma lista padronizada, simplificada e otimizada dos instrumentais odontológicos essenciais para um curso de Odontologia. Simplificar e otimizar o instrumental odontológico exigido para esse curso tende a reduzir o valor financeiro de todo o conjunto, com a aquisição do que realmente é imprescindível para o aprendizado. Essa ação pode colaborar com a permanência de estudantes carentes.

Nas entrevistas são comentadas as dificuldades enfrentadas pelo programa de empréstimo de instrumental dessa universidade. Entre elas, um estudante relatou que de $100 \%$ [do instrumental], (...) consegue 30\%. (...) Hoje (...) já consegue uns $45 \%$ (risos) (E10). Consideram que o problema decorre em virtude da burocracia e morosidade do processo licitatório:

Cadê o resto das coisas que precisa, porque que não compra, qual a dificuldade de fazer a especificação, de botar o produto, de botar o que que é equipamento, de botar o que que é material e mandar pra lá? (...) tem o dinheiro, não tem o pedido, (...) não tem ninguém pra ficar aqui no programa (E8). 
Há relatos ainda da burocracia para o acesso ao programa:

[...] não sei se foi tranquilo, é aquela burocracia, papelada, [para conseguir o instrumental fornecido pela universidade] (E5).

De acordo com os relatos das entrevistas, mesmo quando contemplados pelo empréstimo, os estudantes desse curso não recebem as listas completas e, além disso, alguns instrumentos já estão ultrapassados ou estragados.

(...) porque às vezes os materiais não são da qualidade que às vezes os professores requerem. Então você vai lá, pega o material $e$ às vezes você vai fazer o procedimento e realmente você vê que é dificil (E10).

[...] os materiais (fornecidos pela Universidade), são muito ruins, enferrujados, são muito ruins, são péssimos! (E9).

A opinião desse estudante não é unânime entre os entrevistados, no entanto, relatos semelhantes apareceram em outras cinco entrevistas (E2, E7, E8, E10, E11).

Um estudante relatou que a baixa qualidade de certos instrumentos cedidos pela Universidade prejudicou seu desempenho durante a execução de procedimentos odontológicos em aula de laboratório.

[...] Mas a gente que tava com uma coisa emprestada ali, mais antiga, a gente tinha alguns obstáculos. [Descreve as dificuldades no procedimento] Então aí passava por aquele constrangimento, $e$ demorava... atrasava... (E7).

Sendo assim, os estudantes contemplados por esse programa de empréstimo devem adquirir, com recursos próprios, o que falta para completar as listas exigidas pelos professores, como falou este entrevistado: Nossa, quando, por exemplo, não tem o instrumental, a gente compra. Eu tenho vários materiais que eu mesmo comprei (E7).
Além dos instrumentos, o curso exige uma grande quantidade de materiais de consumo e descartáveis. O material que não é fornecido pela Universidade, como luvas e máscaras, deve ser adquirido por todos os estudantes do curso e eles confirmaram que tem que comprar todo material descartável (E8) e ainda que algumas coisas do consumo a gente tem aqui, só que é muito limitado, né? (...) Mas a gente compra (E7).

São diversas as formas e caminhos utilizados pelos estudantes para conseguirem o que necessitam para usufruírem do conhecimento advindo das aulas práticas: eu tentava (...), ia na dental, comprava apertada e ia parcelando (E9); minha mãe recebeu o décimo-terceiro salário, aí foi o $13^{\circ}$ dela todinho (E3); a gente dá um jeito, vende alguma coisa (E3); a gente fez uma compra conjunta da turma, aí ficou mais barato (E11); as dentais - lojas de produtos odontológicos - acabam facilitando os parcelamentos (E13).

No entanto, o estresse relatado pelos estudantes para a aquisição de pelo menos a lista mínima do que necessitam está explícito na fala:

E assim, a gente fica muito prejudicado porque quando começou as aulas desse semestre eu tava louca na [Coordenação do curso], tipo assim, tava tendo aula lá e tava tendo que vim aqui na [Coordenação do curso], saber se já conseguiu, já conseguiu, o que eu vou ter que fazer... (E8).

A questão do instrumental e material exigidos no curso de Odontologia, apesar de todos os esforços da IFES e dos estudantes e familiares, dificulta a permanência e figura como fator de exclusão.

\section{Discriminação}

De acordo com os entrevistados, a demanda pelo instrumental odontológico gerou manifestações de discriminação de alguns poucos professores do curso.

Estudantes relataram que, por sua condição financeira, só conseguem adquirir instrumental de qualidade inferior, que custa menos nas lojas 
especializadas. Um estudante relatou que tem colegas que tem muita dificuldade financeira (...) compra o mais barato (E12). Manifestaram ainda a incompreensão do professor, alegando que ele não entende que aquilo lá é porque você não tem condição de comprar (E9), posição docente que faz com que eles sintam a discriminação.

Nas aulas práticas, o docente se utiliza do instrumental do aluno para fazer demonstração dos procedimentos odontológicos. Os relatos revelam uma indisposição de professores ao experimentarem um equipamento diferente do que estão habituados, como no relato a seguir: Aí eu falei: mas não dá para fazer com esse? [instrumento], ele [o professor], não, dá, aí eu falei: uai gente, se dá pra fazer, prá que ficar falando, ainda mais falar alto demais (E15).

A fala revela que a forma como alguns docentes abordam os estudantes que não cumprem com todas as exigências é motivo de constrangimento para muitos e, nesse caso, de acordo com os entrevistados, não se comportam assim apenas com os cotistas nem somente com os que se utilizam do empréstimo da universidade. Os estudantes são submetidos a humilhação pública, pois os professores falam alto quando exigem uma marca específica ou quando criticam o instrumental do aluno, sem se preocuparem com outras pessoas que possam estar ao redor.

Cruz e Pereira (2013) ${ }^{27}$ discorrem sobre as relações de poder no ambiente universitário e afirmam que estas definem o lugar do discente e do docente, este último se enquadrando no topo da hierarquia. Sendo assim, os professores universitários intentam legitimar seus valores nesse ambiente e na relação com os estudantes. Ainda segundo os mesmos autores, o ambiente universitário reproduz as relações sociais, portanto, estampa os embates de classe, de etnia e de gênero.

Nas entrevistas, houve relatos repetitivos sobre docente que diminui a nota de estudantes tão somente pela qualidade do instrumental utilizado pelo discente, como a fala a seguir:
Agora tem uma coisa na [faculdade] que é ruim, é um aluno ser discriminado pelo seu instrumental (...) e eu já vi alunos perderem notas... (E12).

Diante de tal realidade, sugere-se rever as práticas de avaliação que muitas vezes são repetidas sem se ater a seu propósito. Qualquer pessoa que passou pelos cursos de Odontologia deve lembrar-se desse momento de conferência de instrumental. Por que mesmo fazemos isto? A falta de algum item deve reverter-se em diminuição da nota do aluno? Qual o aprendizado que esta prática resulta na formação de um cirurgião-dentista? Pois nesse momento os entrevistados percebem e se ressentem com a discriminação e a injustiça a que são submetidos rotineiramente por alguns professores:

Se eu não tiver instrumental (...) eles não vão considerar se eu tive dificuldade ou não pra comprar, eu tenho que tá com o material (...) Cobram, cobram o material, a qualquer custo entendeu? (E13).

Um estudante, inclusive, declarou que mudou de turma, pois um professor não assistia a ele e a outros colegas que se utilizavam de um equipamento antigo emprestado pela Universidade, como assistia a outros que possuíam esse equipamento novo ou em melhores condições.

E aí ele [o professor] percebeu que todo mundo tinha um padrão [de instrumento odontológico] (...) e eu e mais duas amigas, diferente. E aí ele já chegou na gente $e$ referiu que tava sujo, e que o material era velho, que essa marca não era boa... Tanto que eu e mais outra colega mudamos de turma, porque a gente se sentiu super reprimida por causa disso, a gente sentia que a gente não era tão assistida quanto as outras pessoas, ele fazia até um pouco de pouco caso mesmo (E7).

A pesquisa de Neves, Faro, Schmitz (2016) ${ }^{9}$ objetivou conhecer as mudanças ocorridas na Universidade Federal de Sergipe, após a 
implantação das ações afirmativas e encontrou tensões entre professores e alunos. Os entrevistados citaram professores que desqualificam os estudantes beneficiários de cotas, principalmente nos cursos elitizados. Estudo realizado na Universidade Federal do Espírito Santo (UFES) avaliou a relação professores/alunos de Odontologia $^{28}$ e encontrou que $65 \%$ dos alunos pesquisados desse curso, afirmaram terem sido repreendidos por professores na frente de pacientes pelo menos uma vez. Relataram também sentimento de superioridade, arrogância e autoritarismo por parte de docentes e que estes atuam com paternalismo com determinados estudantes e com exclusão em relação a outros.

Não foram encontrados trabalhos na literatura relacionando a dificuldade de aquisição do instrumental odontológico e a manifestação de discriminação por esse motivo, como encontrado nos relatos dos entrevistados deste estudo.

\section{CONCLUSÕES}

A partir dos resultados desta pesquisa, verificou-se que os entrevistados enfatizaram o suporte familiar e a cooperação de colegas, professores e funcionários técnico-administrativos. Especialmente os estudantes de baixa renda reconhecem o programa de empréstimo de instrumental odontológico da Universidade como uma ação de inclusão, que pode evitar ou diminuir a evasão do curso. No entanto, a dificuldade da Universidade em emprestar todo instrumental exigido e a baixa qualidade de alguns itens figuram como mecanismo de exclusão, pois diante disso muitos estudantes entrevistados enfrentam cotidianamente as dificuldades de aquisição do aparato material considerado obrigatório, junto a outras demandas relacionadas a sua própria subsistência. Além disso, os entrevistados se sentem discriminados por alguns professores que não aceitam os instrumentais que eles possuem e até retiram nota quando falta um instrumento ou ele foge do padrão de qualidade esperado.
Para que os programas de assistência estudantil possam abranger a totalidade de estudantes que deles necessitam, os investimentos do Governo Federal para o PNAES devem ser não só mantidos como ampliados. É necessário ainda que a direção da Instituição tome as devidas providências para garantir que os cotistas sejam respeitados e valorizados em seus direitos frente à Comunidade Universitária e, mais especificamente, frente aos professores do curso. Esta estratégia poderia ser adotada com a implementação de ações de educação permanente do corpo docente.

\section{ABSTRACT \\ Dentistry quota students and dental instruments}

The Quota Policy for higher education in Brazil proposes to reserve vacancies for black, brown and indigenous students from public and lowincome schools. The acquisition of the required instruments in the dentistry course represents a difficulty for the permanence on the course for most of these students. The objective of this study was to understand the experience of quota students regarding the acquisition and use of instruments and materials for the practical classes of an undergraduate course in dentistry. Qualitative research was conducted through semi-structured interviews with 16 students chosen at random from all years of the course, and from all quota groups according to Law 12.711 / 2012. The treatment of the data was based on the thematic modality of Content Analysis, from which three categories emerged: "Inclusion", "Exclusion" and "Discrimination". The support of the university community, family and colleagues appears as an inclusion mechanism, as it favors the permanence of these students, as well as the instrumental loan program for low-income students of this University. On the other hand, the program was also considered an exclusion factor because it did not offer all the requested instruments and some were of low quality. Respondents reported being discriminated against by a small number of teachers and 
feeling excluded when using non-standard instruments. The challenge for the researched institution is to guarantee the adequate material conditions for the education of these students, to propose strategies for the improvement of the instrumental program and to implement actions aiming at teacher development.

Descriptors: Affirmative Action. Dentistry Student. Dentistry. Public Policy. Universities.

\section{REFERÊNCIAS}

1. Dias Sobrinho J. Democratização, qualidade e crise da educação superior: faces da exclusão e limites da inclusão. Educ Soc. 2010; 31(113): 1223-45.

2. Souza AC, Brandalise MAT. Democratização, justiça social e igualdade na avaliação de uma política afirmativa: com a palavra, os estudantes. Ensaio: Aval Pol Públ Educ. 2015; 23(86): 181-212.

3. Bezerra TOC, Gurgel CA. A política pública de cotas em Universidades, Desempenho Acadêmico e Inclusão Social. SBIJ. 2011; (9):1-22.

4. Brasil. Lei $\mathrm{n}^{\circ} 12.711$, de 29 de agosto de 2012. Lei de Cotas: dispõe sobre o ingresso nas universidades federais e nas instituições federais de ensino técnico de nível médio. Diário Oficial da União. 30 ago 2012; Seção 1. p 1-2.

5. Cunha EMP. Sistema universal e sistema de cotas para negros na universidade de Brasília: um estudo de desempenho [Tese]. Brasília: Universidade de Brasília - UNB; 2006.

6. Resende ACA, Queiroz EMO, Faria GGG. A dialética inclusão/exclusão na experiência do programa UFGInclui. Rev Bras Est Pedag. 2012 jan/abr; 93(23): 120-34.

7. Fórum Nacional de Pró-Reitores de Assuntos Comunitários e Estudantes (FONAPRACE). IV Pesquisa do Perfil Socioeconômico e Cultural dos Estudantes de Graduação das Instituições Federais de
Ensino Superior Brasileiras. 2016 [acesso em 09 set 2019]. Disponível em: http://www.andifes.org.br/wp-content/ uploads/2017/11/Pesquisa-de-Perfil-dosGraduanso-das-IFES_2014.pdf.

8. Lemos IB. Narrativas de cotistas raciais sobre suas experiências na universidade. Rev Bras Educ. 2017; 22(71):1-25.

9. Neves PSC, Faro A, Schmitz H. As ações afirmativas na Universidade Federal de Sergipe e o reconhecimento social: a face oculta das avaliações. Ensaio: Aval Pol Públ Educ. 2016; 24(90):127-60.

10. Brasil. Decreto $n^{\circ} 7.234$, de 19 de julho de 2010. Institui o Plano Nacional de Assistência Estudantil - Pnaes. Diário Oficial da União. 2010 jul 20; Seção 1. p. 1-2.

11. Minayo MCS. O Desafio do Conhecimento: Pesquisa Qualitativa em Saúde. 14 ed. São Paulo: Hucitec; 2014.

12. Bardin L. Análise de Conteúdo. 1 ed rev e amp. São Paulo: Edições 70; 2016.

13. Moraes R. Análise de Conteúdo. Rev Educ. 1999; 22(37): 7-32.

14. Minayo MCS (org.), Deslandes SF, Gomes R. Pesquisa social: Teoria, método e criatividade. 34 ed. Petrópolis: Vozes; 2015.

15. Zunino LMR, Bastos JLD, Coelho IZ, Massignam FM. A discriminação no ambiente universitário: quem, onde e por quê? Sau \& Transf Soc. 2016; 6(1): 13-30.

16. Toassi RFC, Souza JM, Rosing CK, Baumgarten, A. Perfil sociodemográfico e perspectivas em relação à profissão do estudante de Odontologia da Universidade Federal do Rio Grande do Sul, Brasil. Rev Facul Odontol Porto Alegre. 2011; 52(1/3):25-32.

17. Ristoff D. Perfil socioeconômico do estudante de graduação: uma análise de dois ciclos completos do Enade (2004 a 2009). Flacso Brasil, Cadernos do GEA 2013; (4): $1-32$. 
18. Universidade Federal do Pará [homepage na Internet]. [Acesso em 9 set 2019]. Disponível em: http://saest.ufpa.br/portal/.

19. Universidade Federal do Maranhão [homepage na Internet]. [Acesso em 9 set 2019]. Disponível em: http://portais.ufma. br/PortalProReitoria/proaes/paginas/pagina _estatica.jsf?id=942.

20. Universidade Federal de Uberlândia [homepage na Internet]. [Acesso em 9 set 2019]. Disponível em: http://www.ufu. br/assistencia-estudantil.

21. Mayorga C, Souza LM. Ação Afirmativa na Universidade: a permanência em foco. Ver Psicol Polit. 2012; 12(24):263-81.

22. Souza JM, Sousa MG, Toassi RFC. Democratização do acesso à educação superior pública a partir do REUNI: o curso noturno de Odontologia da Universidade Federal do Rio Grande do Sul. Criar Educação: Rev Program Pós-Grad em Educ - UNESC. 2015; 4(1): 1-21.

23. Latreille AC, Sobrinho SM, Warmling AMF, Ribeiro DM, Amante CJ. Perfil socioeconômico dos graduandos em Odontologia da Universidade Federal de Santa Catarina. Rev ABENO. 2015; 15(1): 86-96.

24. Santos BRM, Gonzales PS, Carrer FCA, Araújo ME. Perfil e expectativas dos ingressantes da Faculdade de Odontologia da USP: uma visão integrada com as diretrizes curriculares nacionais e o Sistema Único de Saúde. Rev ABENO. 2015; 15(1): 28-37.
25. Brasil. Ministério da Saúde. Portaria $\mathrm{n}^{\circ}$ 1.646, de 5 de agosto de 2014. Institui o componente GraduaCEO - BRASIL SORRIDENTE, no âmbito da Política Nacional de Saúde Bucal, que irá compor a Rede de Atenção à Saúde (RAS), e dá outras providências. Diário Oficial da União. 2014 ago, 5.

26. Morita MC, Amante CJ, Tanaka EE, Porto NA, Hayassy A, Miguel LCM, et. al. Instrumentais Odontológicos essenciais para a graduação em Odontologia. Rev ABENO. 2016; 16(Supl1): 3-35.

27. Cruz GV, Pereira WR. Diferentes configurações da violência nas relações pedagógicas entre docentes e discentes do ensino superior. Rev Bras Enf. 2013; 66(2): 241-50.

28. Cavaca AG, Esposti CDD, Santos-Neto ET, Gomes MJ. Relação professor-aluno no ensino da odontologia na Universidade Federal do Espírito Santo. Trab Educ Saúde. 2010; 8(2): 305-318.

\section{Correspondência para:}

Ângela Barbosa Martins

e-mail: angelabarmartins@gmail.com

Rua 217, 930/202, setor Leste Universitário, 74603-090 Goiânia/GO 